\title{
The Effect of Using a Rocker Arm on the Performance and Efficiency of a 200cc 4 Stroke Motor
}

\section{Pengaruh Penggunaan Rocker Arm Terhadap Performa dan Efesiensi Motor 4 Stroke 200cc}

\author{
Afif Fakhruddin Alfahmi ${ }^{1}$, A'rasy Fahruddin ${ }^{2}$ \\ \{afif56996@gmail.com ${ }^{1}$, arasy.fahruddin@umsida.ac.id $\left.{ }^{2}\right\}$
}

Program Studi Teknik Mesin, Fakultas Sains dan Teknologi, Universitas Muhammadiyah Sidoarjo

\begin{abstract}
In Indonesia, many people often use two-wheeled vehicles compared to four-wheeled vehicles, and so many people want the best speed and performance of their motorbikes compared to the manufacturer's standards. Modifying the camshaft or what is more familiarly known as "papas noken or camshaft" aims to increase volumetric efficiency and change the character of an engine, so that the engine produces more power and as needed. In racing motorbikes, modifications have been made to several systems and components, including the camshaft or camshaft to improve the motorbike's performance. Motor vehicle engine performance parameters include torque, power, mean effective pressure, specific fuel consumption, thermal efficiency, and air-material ratio. fuel air and fuel. In general, motorbikes for competition have been modified mechanical components and systems.
\end{abstract}

Keywords - camshaft; 200cc 4 stroke motorcycle

\begin{abstract}
Abstrak. Di indonesia banyak orang yang sering memakai kendaraan bermotor roda dua dibandingkan dengan roda empat, dan begitu banyak pula orang yang menginginkan kecepatan dan performa motornya yang terbaik dibandingan dengan standart pabrikanya. Memodifikasi camshaft atau yang lebih akrab dikenal dengan istilah "papas noken as atau camshaft" bertujuan untuk meningkatkan efesiensi volumetrik dan merubah karakter sebuah mesin, agar mesin menghasilkan tenaga yang lebih besar dan sesuai kebutuhan. Pada motor balap telah dilakukan modifikasi pada beberapa sistem dan komponenya di antaranya yaitu camshaft atau noken as untuk meningkatkan unjuk kerja sepeda motor tersebut. Parameter-parameter unjuk kerja mesin kendaraan bermotor antara lain adalah torsi (torque), daya (power), tekanan efektif rata-rata (mean effective pressure), konsumsi bahan bakar spesifik (spesific fuel consumption), efesiensi termal, dan perbandingan udara - bahan bakar udara dan bahan bakar. Pada umumnya sepeda motor untuk kompetisi telah di modifikasi komponen dan sistem mekanisnya.
\end{abstract}

Kata kunci - camshaft; Sepeda motor 4 langkah 200cc

\section{PENDAHULUAN}

Di indonesia banyak orang yang sering memakai kendaraan bermotor roda dua dibandingkan dengan roda empat, dan begitu banyak pula orang yang menginginkan kecepatan dan performa motornya yang terbaik dibandingan dengan standart pabrikanya. Memodifikasi camshaft atau yang lebih akrab dikenal dengan istilah "papas noken as atau camshaft" bertujuan untuk meningkatkan efesiensi volumetrik dan merubah karakter sebuah mesin, agar mesin menghasilkan tenaga yang lebih besar dan sesuai kebutuhan. Tanpa disadari, modifikasi pada camshaft sepeda motor untuk kompetisi balap dapat diaplikasikan pada sepeda standart yang biasanya digunakan dalam aktifitas sehari-hari. Maka dilakukan riset untuk memapas camshaft sepeda motor 200cc, agar modifikasi pada camshaft sepeda motor untuk kompetisi balap bisa di aplikasikan pada sepeda motor standart bertujuan untuk optimalisasi kinerja motor bakar 4 langkah [2].

Pada umumnya sepeda motor untuk kompetisi telah di modifikasi komponen dan sistem mekanisnya. Komponen yang di modifikasi antara lain sistem bahan bakar, pengapian, rangka, pemindah daya, volume silinder [3].

Tanpa disadari, modifikasi pada camshaft sepeda motor untuk kompetisi balap dapat diaplikasikan pada sepeda standart yang biasanya digunakan dalam aktifitas sehari-hari. Maka dilakukan riset untuk memapas camshaft sepeda motor 200cc, agar modifikasi pada camshaft sepeda motor untuk kompetisi balap bisa di aplikasikan pada sepeda motor standart bertujuan untuk optimalisasi kinerja motor bakar 4 langkah.

\section{METODE}

\section{A. Diagram alur penelitian}

Diagram alur dari Memangkas Atau Memodifikasi Camshaft Standart Untuk Sepeda Motor Cylinder 200CC ini adalah sebagai berikut ini : 
B. Variabel penelitian

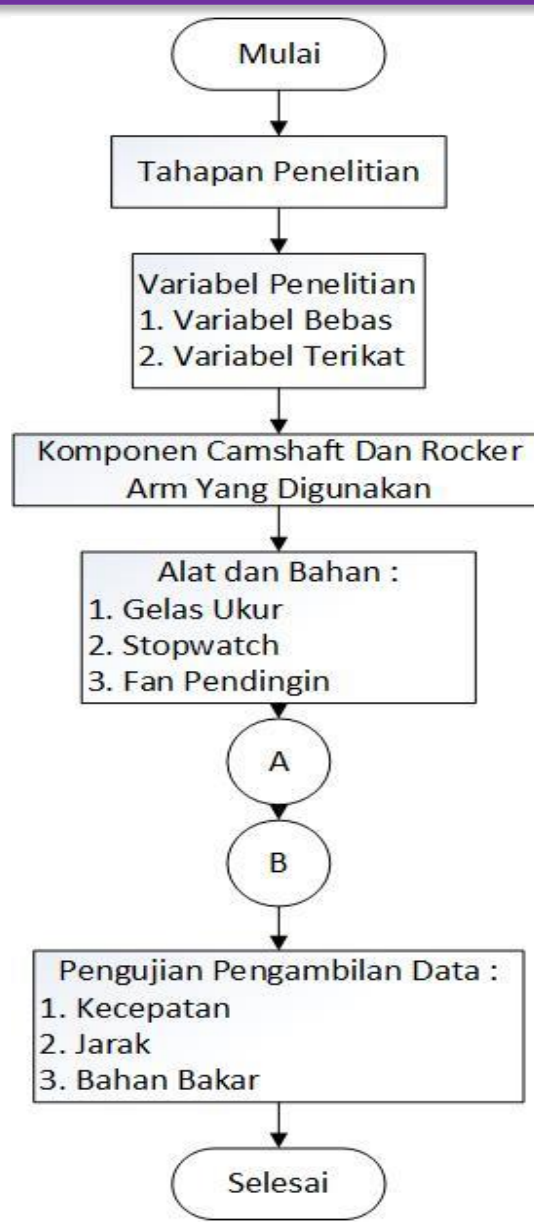

Variabel Bebas

Variabel bebas adalah variabel yang menjadi penyebab atau memengaruhi, meliputi faktor-faktor yang diukur, dimanipulasi atau dipilih oleh peneliti, tujuannya agar dapat menentukan hubungan antara fenomena yang diobservasi atau diamati. Yang pertama di sini peneliti mengamati camshaft standart pabrikan dengan durasi $260^{\circ}$,

Variabel Terikat

- Torsi dan daya

Besarnya kontribusi durasi camshaft dan waktu pengapian terhadap respon torsi dan daya. Metode penelitian ini yaitu merubah durasi camshaft dari standar pabrik yaitu $260^{\circ}$ menjadi $280^{\circ}$ dan $290^{\circ}$, sedangkan waktu pengapian dirubah dari standar $\left(0^{\circ}\right)$ menjadi $+15^{\circ}$ dan $-15^{\circ}[10]$.

- Efesiensi

Efisiensi mesin diukur dari banyak hal, mulai kemampuan mesin menahan panas, kemampuan mesin menghisap volume campuran udara- bahan bakar, seberapa efisien mesin mampu menggerakkan semua komponen dengan gesekan minimum, dan banyak nilai-nilai efisiensi kerja lainnya untuk peningkatan performa.

\section{HASIL DAN PEMBAHASAN}

\section{A. Percobaan Penelitian Roller Rocker Arm Terhadap Camshaft Modifikasi}

Percobaan dilakukan terhadap motor dalam keadaan standart maupun dengan motor yang ditambah modifikasi camshaft. Pengujian dilakukan dengan menggunakan mesin sepeda motor yang berkapasitas 200 cc, Untuk mengetahui efisiensi konsumsi bahan bakar. Spesifikasi noken as yang dirancang di dapatkan hasil sebagai berikut :

Tipe temlar atau rocker arm : temlar roller.

Diameter : $20 \mathrm{~mm}$

Y : $31,7 \mathrm{~mm}$

$\mathrm{X}: 28,6 \mathrm{~mm}$ 
Procedia of Engineering and Life Science Vol.1 No. 1 March 2021

Seminar Nasional \& Call for Paper Fakultas Sains dan Teknologi (SENASAINS 1st)

Universitas Muhammadiyah Sidoarjo

Ratio : $1: 1: 10$

Tipe noken as atau camshaft : standart dan modifikasi

1. Noken as standart Diameter pinggang : $25 \mathrm{~mm}$ Lift : $6 \mathrm{~mm}$.

2. Noken as modifikasi 1 Diameter pinggang : $21 \mathrm{~mm}$ Lift : $8 \mathrm{~mm}$

3. Noken as modifikasi 2 Diameter pinggang : $25 \mathrm{~mm}$ Lift : 9,2 $\mathrm{mm}$

4. Jenis bahan bakar: premium

Tabel 1. Data Konsumsi Bahan Bakar Roller Rocker Arm Dengan Camshaft Standart.

\begin{tabular}{cccccc}
\hline Pengujian ke & $\begin{array}{c}\text { Kecepatan } \\
(\mathrm{km} / \mathrm{jam})\end{array}$ & $\begin{array}{c}\text { Bahan bakar } \\
\text { awal }\end{array}$ & $\begin{array}{c}\text { Bahan bakar } \\
\text { sisa }\end{array}$ & $\begin{array}{c}\text { Konsumsi } \\
\text { bahan bakar }\end{array}$ & Rata-rata \\
\hline 1 & $90 \mathrm{~km} / \mathrm{jam}$ & $1000 \mathrm{ml}$ & $900 \mathrm{ml}$ & $100 \mathrm{ml}$ & \\
2 & $120 \mathrm{~km} / \mathrm{jam}$ & $1000 \mathrm{ml}$ & $800 \mathrm{ml}$ & $200 \mathrm{ml}$ & $100 \mathrm{ml}$ \\
3 & $135 \mathrm{~km} / \mathrm{jam}$ & $1000 \mathrm{ml}$ & $650 \mathrm{ml}$ & $350 \mathrm{ml}$ & \\
\hline
\end{tabular}

Tabel 2. Data Konsumsi Bahan Bakar Roller Rocker Arm Dengan Camshaft Modifikasi 1.

\begin{tabular}{cccccc}
\hline Pengujian ke & $\begin{array}{c}\text { Kecepatan } \\
(\mathrm{km} / \mathrm{jam})\end{array}$ & $\begin{array}{c}\text { Bahan bakar } \\
\text { awal }\end{array}$ & $\begin{array}{c}\text { Bahan bakar } \\
\text { sisa }\end{array}$ & $\begin{array}{c}\text { Konsumsi } \\
\text { bahan bakar }\end{array}$ & Rata-rata \\
\hline 1 & $90 \mathrm{~km} / \mathrm{jam}$ & $1000 \mathrm{ml}$ & $850 \mathrm{ml}$ & $150 \mathrm{ml}$ & \\
2 & $120 \mathrm{~km} / \mathrm{jam}$ & $1000 \mathrm{ml}$ & $750 \mathrm{ml}$ & $250 \mathrm{ml}$ & $150 \mathrm{ml}$ \\
3 & $135 \mathrm{~km} / \mathrm{jam}$ & $1000 \mathrm{ml}$ & $625 \mathrm{ml}$ & $375 \mathrm{ml}$ & \\
\hline
\end{tabular}

Tabel 3. Data Konsumsi Bahan Bakar Roller Rocker Arm Dengan Camshaft Modifikasi 2.

\begin{tabular}{cccccc}
\hline Pengujian ke & $\begin{array}{c}\text { Kecepatan } \\
(\mathrm{km} / \mathrm{jam})\end{array}$ & $\begin{array}{c}\text { Bahan bakar } \\
\text { awal }\end{array}$ & $\begin{array}{c}\text { Bahan bakar } \\
\text { sisa }\end{array}$ & $\begin{array}{c}\text { Konsumsi } \\
\text { bahan bakar }\end{array}$ & Rata-rata \\
\hline 1 & $90 \mathrm{~km} / \mathrm{jam}$ & $1000 \mathrm{ml}$ & $800 \mathrm{ml}$ & $200 \mathrm{ml}$ & \\
2 & $120 \mathrm{~km} / \mathrm{jam}$ & $1000 \mathrm{ml}$ & $650 \mathrm{ml}$ & $350 \mathrm{ml}$ & $250 \mathrm{ml}$ \\
3 & $135 \mathrm{~km} / \mathrm{jam}$ & $1000 \mathrm{ml}$ & $500 \mathrm{ml}$ & $500 \mathrm{ml}$ & \\
\hline
\end{tabular}

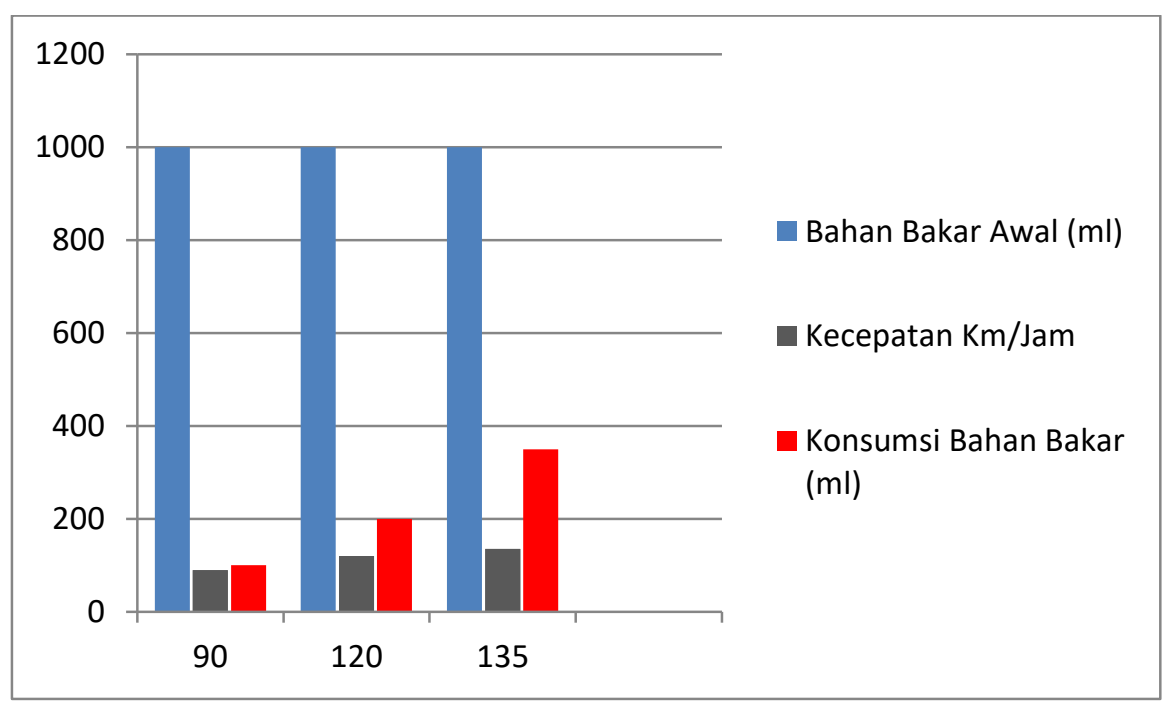

Gambar 2 Grafik Konsumsi Bahan Bakar Menggunakan Roller Rocker Arm Dengan Noken As Standart.

Pada gambar 2 dapat dilihat bahwa dari pengujian diatas, bisa dibandingkan apabila motor bakar 4 tak 200cc jika menggunakan roller rocker arm kecepatanya pun bisa bertambah tanpa menambahkan part ataupun alat yang lainya pada motor tersebut dan konsumsi bahan bakarnya akan semakin boros di karenakan putaran temlar akan semakin cepat dan bukaan klep juga semakin cepat bukaanya. Performa motor akan semakin baik pada saat top speed. Maka gesekan pada roller rocker arm dan noken as standart akan semakin ringan sehingga performa sepeda motor akan semakin baik pada terikan bawah ataupun tarikan atas pada top 
Procedia of Engineering and Life Science Vol.1 No. 1 March 2021

Seminar Nasional \& Call for Paper Fakultas Sains dan Teknologi (SENASAINS 1st)

Universitas Muhammadiyah Sidoarjo

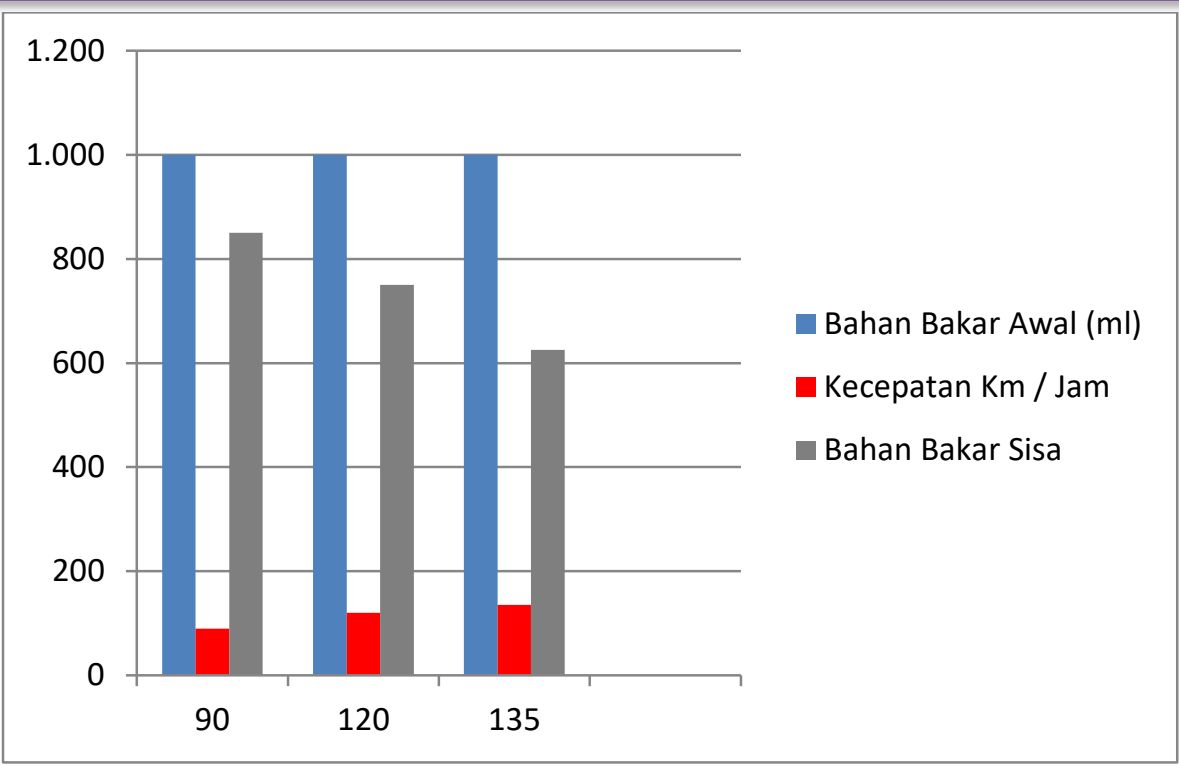

Gambar 3. Grafik Konsumsi Bahan Bakar Menggunakan Roller Rocker Arm Dengan Noken As Modifikasi 1.

Dari gambar 4terlihat bahwa apabila motor 4 tak yang berkapasitas 200cc jika menggunakan roller rocker arm dengan noken as yang sudah di modifikasi diameter pinggang $21 \mathrm{~mm}$ dan untuk lift nya $8 \mathrm{~mm}$, akan sangat terlihat perubahan pada kecepatanya, sedangkan untuk konsumsi bahan bakar yang masuk akan semakin boros. Dibandingkan dengan temlar standart dan noken as standart bawaan pabrik sangat terlihat jauh perbedaanya. Jika menggunakan noken as modifikasi 1 sepeda motor akan semakin terlihat performanya karena gesekan yang semakin ringan dan bukaan klep juga lebih tinggi dibandingan dengan noken as standart, kecepatan motor akan bertambah serta konsumsi bahan bakar akan bertambah juga.

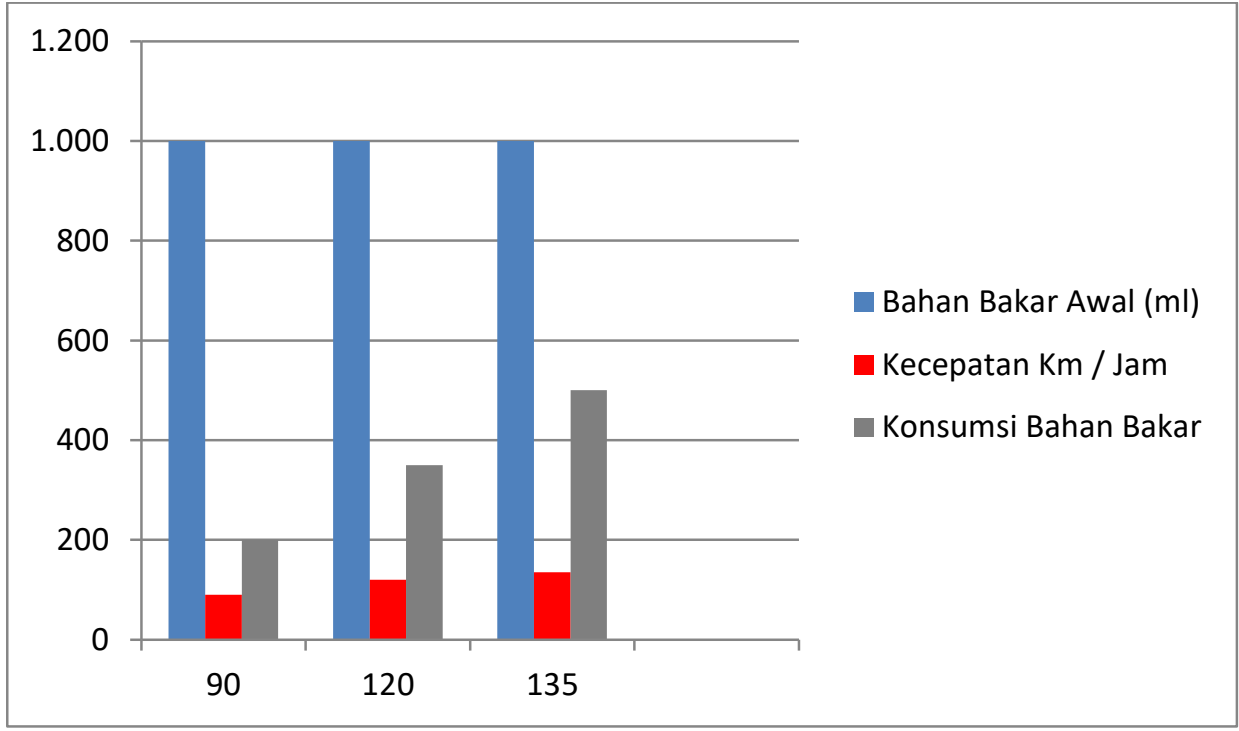

Gambar 4 Grafik Konsumsi Bahan Bakar Menggunakan Roller Rocker Arm Dengan Noken As Modifikasi 2.

Dapat dilihat dari gambar 4 dari beberapa hasil analisa diatas, analisa yang terakhir ini terlihat sangat berbeda, dikarenakan konsumsi bahan bakar lebih banyak masuk atau bisa dikatakan lebih boros lagi dari analisa sebelumnya. Jika menggunakan noken as modifikasi kedua dengan pinggang standart 25mm, tinggi lobe dari bawah 32,8mm, lift valve 9,2mm dibandingkan dengan motor standart yang berkapasitas 200cc yang hanya lift klepnya 6,9mm. Maka tenaga yang dicapai oleh motor tersebut sangat baik, tetapi dengan bertambahnya tenaga atau kecepatan maka konsumsi bahan bakar akan lebih boros lagi dan untuk noken as modifikasi kedua ini hanya digunakan untuk event balap saja. Sedangkan untuk modifikasi noken as 2 ini, konsumsi bahan bakar yang dibutuhkan juga semakin banyak dikarenakan bukaan klep lebih tinggi lagi dibandingkan noken as modifikasi 1 . 
Procedia of Engineering and Life Science Vol.1 No. 1 March 2021

Seminar Nasional \& Call for Paper Fakultas Sains dan Teknologi (SENASAINS 1st)

Universitas Muhammadiyah Sidoarjo

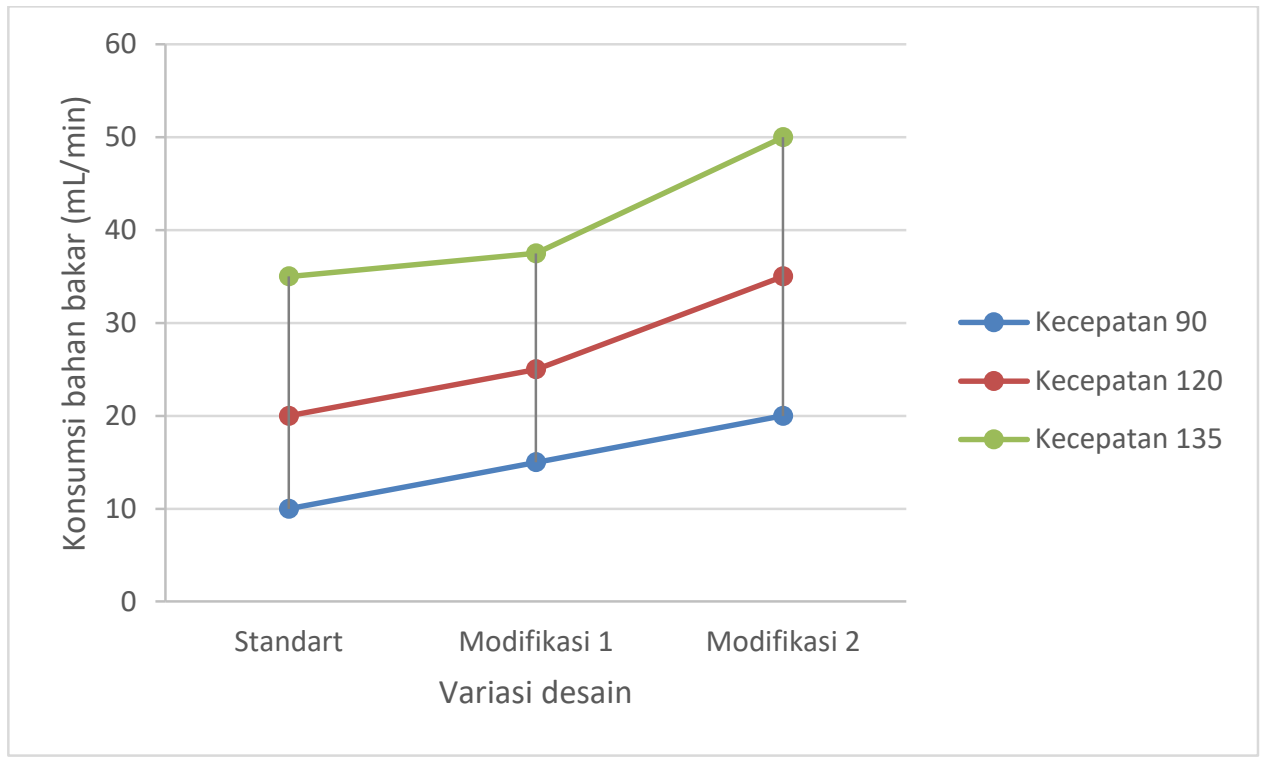

Gambar 5. Grafik hasil variasi desain dengan konsumsi bahan bakar rata-rata.

Jika Noken as atau camshaft standart dengan kecepatan 90km/jam maka bahan bakar yang diperlukan yaitu 100ml / 10menit, apabila sepeda motor menggunakan modifikasi noken as 1 dengan kecepatan 120km/jam maka konsumsi bahan bakar yang diperlukan adalah 200ml, dan jika sepeda motor 200cc ini menggunakan modifikasi noken as 2 dengan kecepatan $135 \mathrm{~km} / \mathrm{jam}$ maka konsumsi bahan bakar yang diperlukan yaitu 350ml dan akan semakin boros karena bukaan klep yang semakin tinggi dan gesekan noken as dengan roller rocker arm yang semakin ringan, sehingga performa sepeda motor akan semakin baik performanya dan kecepatan akan bertambah dibandingkan dengan noken as standart dengan rocker arm standart bawaan pabrik. Sedangkan untuk noken as modifikasi 2 hanya digunakan untuk mesin sepeda motor yang sudah di upgrade keseluruhanya.

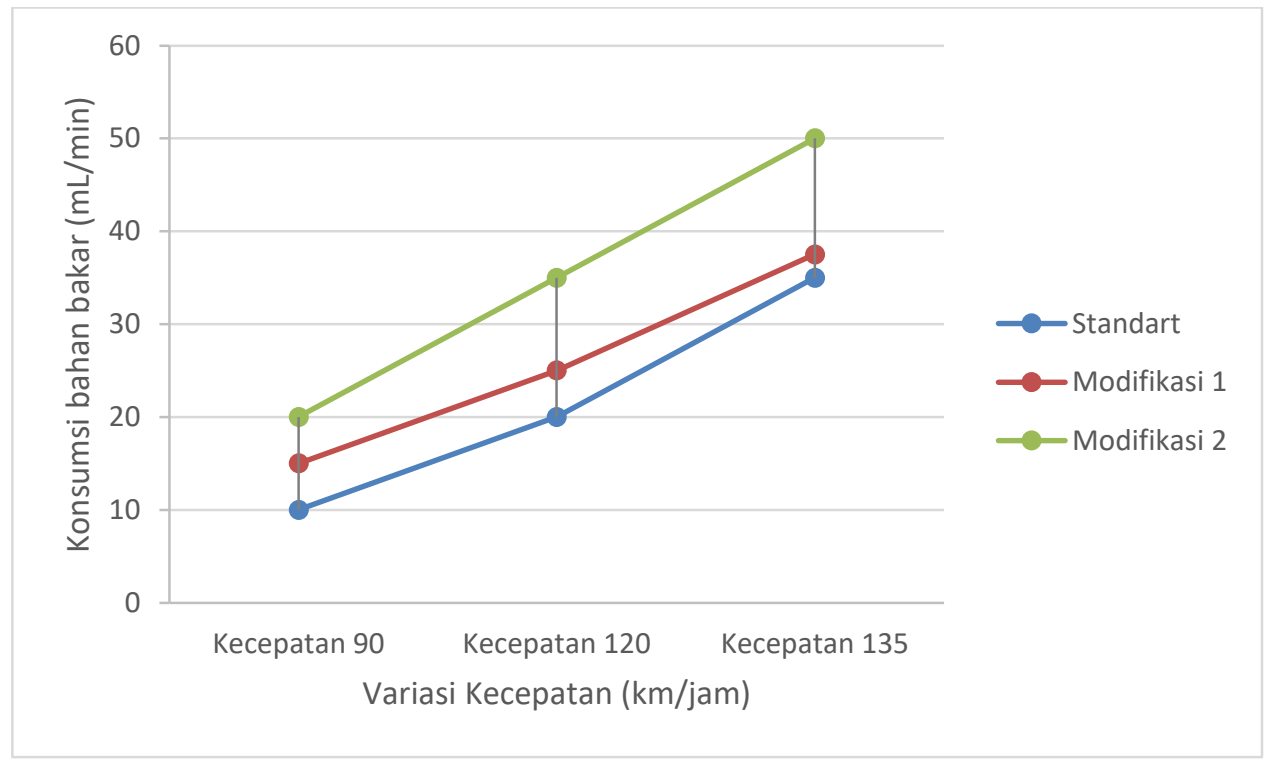

Gambar 6. Grafik hasil variasi kecepatan dengan konsumsi bahan bakar rata-rata

Untuk sepeda motor standart dengan menggunakan roller rocker arm dan noken as standart konsumsi bahan bakar yang di butuhkan lebih boros sedikit dari bawaan pabrik, karena jika menggunakan roller rocker arm maka gesekan antara camshaft dengan roller akan semakin ringan sehingga putaran akan semakin cepat dan bahan bakar yang masuk akan lebih boros dari standartnya. Jika menggunakan noken as modifikasi 1 dengan roller rocker arm gesekan akan semakin ringan dan bukaan klep akan semakin tinggi, sehingga konsumsi bahan bakar yang diperlukan juga semakin banyak dan power tenaga yang dihasilkan akan bertambah dan performa motor akan lebih baik, dan bila motor 
Procedia of Engineering and Life Science Vol.1 No. 1 March 2021

Seminar Nasional \& Call for Paper Fakultas Sains dan Teknologi (SENASAINS 1st)

Universitas Muhammadiyah Sidoarjo

menggunakan roller rocker arm dengan noken as modifikasi 2 konsumsi bahan bakar yang masuk akan bertambah dan pastinya lebih boros dibandingkan dengan profil yang sebelumnya dan lebih baiknya untuk modifikasi noken as 2 ini digunakan pada motor yang sudah di upgrade keseluruhanya yang digunakan untuk event balap.

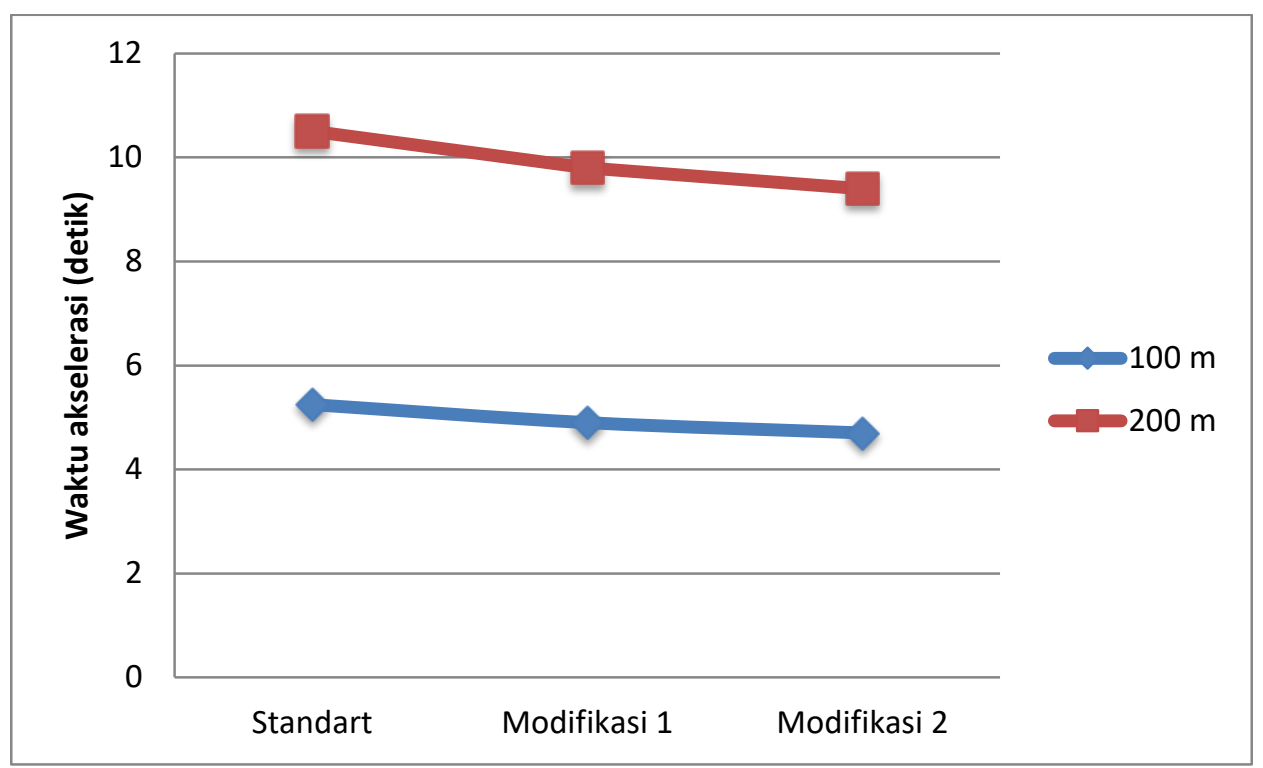

Gambar 7. Grafik akselerasi dengan noken as satandart dan Roller Rocker Arm

Jika noken As atau camshaft standart menggunakan roller rocker arm pada jarak $100 \mathrm{~m}$ akan di ketahui timer akselerasinya 5,25 detik dan pada jarak 200m diketahui akselerasi timernya 10,5 detik, apabila menggunakan camshaft modifikasi 1 dengan roller rocker arm pada jarak 100m akan diketahui timer 4,9 detik sedangkan dengan jarak 200m diketahui timer akselerasinya yaitu 9,8 detik, dan jika camshaft modifikasi 2 menggunakan roller rocker arm pada jarak 100m akan di ketahui timer akselerasi 4,7 detik serta pada jarak 200m akan diketahui 9,4 detik. Untuk camshaft modifikasi 2 ini hanya digunakan untuk event balap tidak cocok digunakan untuk sehari-hari.

\section{KESIMPULAN}

Jika menggunakan noken as modifikasi kedua dengan pinggang standart 25mm, tinggi lobe dari bawah 32,8mm, lift valve $9,2 \mathrm{~mm}$ maka bahan bakar yang dikonsumsi lebih banyak atau boros dari pada camshaft standard. Jika camshaft modifikasi 2 menggunakan roller rocker arm pada jarak 100m akan di ketahui timer akselerasi 4,7 detik serta pada jarak 200m akan diketahui 9,4 detik.

\section{UCAPAN TERIMA KASIH}

Bagian ini menyatakan ucapan terima kasih kepada pihak yang berperan dalam pelaksanaan kegiatan penelitian, misalnya laboratorium tempat penelitian. Peran donor atau yang mendukung penelitian disebutkan perannya secara ringkas.

\section{REFERENSI}

[1] Ardhian Heru Saputra dan Bambang Daryanto Wonoyudo, 2012.” Pola Vibrasi Dari Transmisi V-belt Dibawah Pengaruh Parallel Misaligment”. Fakultas Teknologi Industri, Institut Teknologi Sepuluh November.

[2] Awali Jatmoko dan Ansori."Teknik Mesin Universitas MuhammadiyahMetro”, Halaman 39 - 40.

[3] Azhar Ashari dan M. Miftach Farid dkk,"Rancang Bangun Mesin PenghancurSpuit Bekas" Program Studi D3 Teknik Mesin FTI - ITS Surabaya.

[4] Eko Siswono, 2017.”Rancang Bangun Sepeda Roda Tiga Pasca Stroke Dengan Varian Stang Kemudi Fleksibel Dan Tempat Duduk Fleksibel".'Skripsi Teknik Mesin. Universitas Muhammadiyah Sidoarjo.

[5] Hasan Ibrahim, 2012." Perancangan Mesin Modifikasi Campshaft”. Universitas Negri Yogyakarta.

[6] Khurmi, R.S dan J.K.Gupta, 1989. "Textbook of machine design, eurasia publishing house (pvt) Ltd", Halaman 695 dan 935.

[7] Mahendra Sena, 2016.”Analisa Pengaruh Durasi Campshaft Terhadap Unjuk Kerja Motor Bakar Honda Tiger 
Procedia of Engineering and Life Science Vol.1 No. 1 March 2021

Seminar Nasional \& Call for Paper Fakultas Sains dan Teknologi (SENASAINS 1st)

Universitas Muhammadiyah Sidoarjo

200cc Tune Up Drag Bike.Teknik Mesin Otomotif IKIP Veteran Semarang.

[8] Nugroho Nalaprana dan Sri Agustin, 2015."Analisa Motor Dc Sebagai Penggerak Mobil Listrik”.Universitas Sriwijaya.

[9] Sularso, 1997."Dasar perencanaan dan pemilihan elemen mesin”, jakarta, PT. Pradnya Paramita, halaman 166.

[10] Sularso, 1991. “Dasar perencanaan dan pemilihan elemen mesin”, jakarta, PT. Pradnya Paramita, halaman 173. 